\title{
Uzun Vaka Olarak Sinema Filmlerinin Kullanımına Bir Örnek: The Doctor
}

\section{An Example of Using Cinema Films as a Long Case: The Doctor}

\author{
Müesser Özcan' (ORCID: https://orcid.org/0000-0002-2401-7101) \\ Edip Güvenç Çekiç² (ORCID: https://orcid.org/0000-0002-5605-1953) \\ Ümmühani Özel Tükcü̈ (ORCID: https://orcid.org/0000-0003-2244-7965) \\ Hülya Elbe (ORCID: https://orcid.org/0000-0002-1254-0683) \\ ${ }^{1}$ Muğla Sıtkı Koçman Üniversitesi Tıp Fakültesi Tıp Tarihi ve Etik Anabilim Dalı -Muğla \\ ${ }^{2}$ Muğla Sıtkı Koçman Üniversitesi Tıp Fakültesi Tıbbi Farmakoloji Anabilim Dalı -Muğla \\ ${ }^{3}$ Muğla Sıtkı Koçman Üniversitesi Tıp Fakültesi Tıbbi Biyokimya Anabilim Dalı -Muğla \\ ${ }^{4}$ Muğla Sıtkı Koçman Üniversitesi Tıp Fakültesi Histoloji Embriyoloji Anabilim Dalı -Muğla
}

Sorumlu Yazar:

Doç. Dr. Müesser Özcan

Muğla Sıtkı Koçman Üniversitesi Tıp Fakültesi Tıp Tarihi ve Etik Anabilim Dalı -Muğla

Cep Tel: 05322818800 İş Tel: 025122123213 e-posta: muglabiyomer@gmail.com

Anahtar Sözcükler: sine-eğitim, tıp eğitimi, etik, iyi hekimlik

Keywords:

Cinemeducation, Medical

Education, Good Physician

Gönderilme Tarihi

Submitted:19/12/2018

Kabul Tarihi

Accepted: 06/03/2019

58 kız, 40 erkek toplam 98 öğrenci katıldı.

\section{ÖZET:}

Amaç: Uzun vaka olarak seçilen The Doctor filmi üzerinden klinik öncesi süreçteki tıp fakültesi öğrencilerinin hasta hekim ilişkisinin olumlu ve olumsuz yönleri ile ilişkisinin etik boyutu hakkındaki görüşlerini belirlemek amaçlanmıştır.

Gereç ve Yöntem: Araştırmada filmin yirmi dördüncü dakikasındaki sahne ile final sahnesi için önceden hazırlanan iki adet yarı yapılandırılmış sorgulama formu kullanıldı. Bu sayede öğrencilerin yönlendirilmeden görüşlerini açıklayabilmesine olanak sağlanmıştır. $\mathrm{Bu}$ formlar film izlenirken ilgili dakikalarda öğrencilere dağıtılarak öğrencilerin konu hakkındaki görüşleri alındı. Çalışma gönüllülük bildiren ve filmi izleyip çalışma formunu eksiksiz dolduran öğrencilerle yürütüldü. Çalışmaya

Makale Künyesi: Özcan M, Çekiç EG,Türkcü ÜÖ,Elbe H. Uzun Vaka Olarak Sinema Filmlerinin Kullanımına Bir Örnek: The Doctor. Tip Eğitimi Dünyası. 2019;18(54): 63-75 
Çalışma gönüllülük bildiren ve filmi izleyip çalışma formunu eksiksiz dolduran öğrencilerle yürütüldü. Çalışmaya $58 \mathrm{kız}, 40$ erkek toplam 98 öğrenci katıldı. verilerin içerik analizi MAXQDA software kullanılarak yapılmıştır. İçerik analizinde tema, kod belirlenmiş ve sözcük bulutu yapılmıştır.

Bulgular: Hasta hekim ilişkisinde hekimin erken tanı koyması, etkin tedavi planı yapması sergilediği hekimlik bilgi ve becerileri ögrenciler tarafindan olumlu yönler olarak belirlendi. Bununla birlikte hekimin kötü haberi vermedeki başarısızlı̆̆ yaklaşım sergilememesi, işlemler sürecinde hastaya bilgilendirme yapmaması, hastay1 dinlememesi ve meslektaşına gösterilmesi gereken deontolojik yaklaşımın sergilememesi gibi tutumlar olumsuz hekim tutumları olarak sıralandı. Kız öğrenciler erkek öğrencilerden daha fazla oranda; hekimin kötü haberi çok başarısız verdiği, empatik yaklaşım göstermediği ve meslektaşına uygun deontolojik yaklaşım sergilemediği görüşündeydi. Hekim adaylarının hastanın yaşadıklarını anlayabilmesi için hastanede hasta olarak kalmalarının istendiği sahneye ilişkin, öğrencilerin \%63,3'ü böyle bir deneyime gerek olmadığını ve bu becerinin eğitimle kazanılabilir olduğunu bildirirmiştir. Bununla birlikte daha önce hastaneye yatış deneyimine sahip olan öğrenciler hastalı̆̆ın ve hastaneye yatmanın hastayı anlamaya büyük katk1 sağlayacağı inancındaydı.

Sonuç: Klinik öncesi süreçteki tıp fakültesi öğrencileri; uzun vaka olarak seçilen filmideki hikaye üzerinden mesleki bilgi ve becerinin önemi, kötü haberi verme, empatik yaklaşım sergileme, hasta olan bir meslektaşıyla kuracağ ilişkinin doğası ve hastalık sürecini deneyerek öğrenme gibi karmaşık etik konular hakkında görüş bildirebilmişlerdir. Böylelikle öğrencilerin iyi bir hekimin sahip olması gereken temel özellikleri hakkındaki düşüncelerine ilişikin ipuçları da elde edilebilmiştir.

\section{ABSTRACT:}

Background: The aim of this study was to determine the positive and negative aspects of medical faculty students in the pre-clinical period regarding the patient-doctor relationship and the ethical dimension of this relationship through the film of "The Doctor" selected as a long case.

Methods: Two semi-structured questionnaires prepared for the final scene and the set in the twenty-fourth minute of the film were used. Therefore, the students were able to explain their opinions without being guided. These forms were handed out to the students in the related minutes and their opinions about the issue were received. The study was conducted with voluntary students who watched the film and filled the form completely. Totally 98 students including 58 female and 40 male students participated in the study.

Results: The early diagnosis of the physician in the patient-doctor relationship, making an effective treatment plan and the knowledge and skills of the physician were determined as the positive attitudes by the students. However; the failure of the physician in terms of sharing bad news, not showing any empathy, not informing the patient during the procedures, not listening the patient and not showing a deontological approach to his colleague were listed as negative attitudes of the physician. Female students were found to be more than male students having the opinion that the physician shared the bad news very unsuccessfully, did not show any empathy and did not present appropriate deontological approach to his colleague. Regarding the scene when the doctor candidates were asked to be hospitalized as a patient in order to understand the patient's experiences; $63.3 \%$ of the students reported that 
such an experience was not necessary and that this skill could be acquired through education. On the other hand, students with previous hospitalization experience believed that the disease and hospitalization would contribute greatly in terms of understanding the patient.

Conclusions: Medical faculty students in the pre-clinical period were able to express their views on complex ethical issues such as the importance of professional knowledge and skills, delivering bad news, showing an empathic approach, the nature of the relationship with a sick colleague and learning by trying the process of illness through the story in the film selected as the long case. Thus, clues were obtained about the opinions of the students regarding the basic characteristics of a good physician.

\section{Giriş}

Özellikle son otuz yılda; bilgi ve beceri olarak yetkin bir klinisyen, iyi bir dinleyici, gözlemci, karşısındaki bireylere ve durumlara duyarlı bir iletişimci olarak mezun verebilmek tıp fakültelerinin ortak amacı olmuştur. Bu amaca ulaşmada; entegre eğitim, probleme dayalı öğrenme, karma eğitim, simüle hasta eğitimi ve kanıta dayalı tıp uygulamaları gibi çeşitli eğitim metotlarına başvurulmaktadır (1-4). Ülkemizde de aynı tarihlerde başlayan bu tür çalışmalar, son yıllarda mezuniyet öncesi tıp eğitimi ulusal standartlarının belirlenmesi ve fakültelerin akreditasyon talepleriyle yeni bir aşamaya gelmiştir. Son yıllarda tıp eğitiminin niteliğini artırmaya yönelik girişimler planlanırken iyi hekim yetiştirmede büyük önemi olan çeşitli değer, tutum, davranış ve becerilerin kazandırılmasına yönelik uygulamalara eğitim programlarına daha çok yer verildiği görülmektedir. $\mathrm{Bu}$ süreçte tıp fakültelerinin eğitim programlarına giren "iyi hekimlik" değerleri ile tanımlanan bu yeni model, tıp eğitiminde önemli değişim-gelişim yaşanmasına yol açmıştır (5-9). Bu eğitimin içeriğinde; hasta, hasta yakını ve hekim arasındaki iletişim becerilerini geliştirme, erken dönemde klinik ziyaret ile farkındalık sağlama, öğrencilere farklı bakış açıları kazandıran tıpta insan bilimleri etkinlikleri, hekimlik mesleğinin etik değerleri gibi konular yer almaktadır. Böylelikle özellikle tıp eğitimine erken dönemde etik değerler, hekimlik erdemleri gibi kavramlar entegre edilebilmektedir (6, 9-11). Tıp etiği eğitiminin temel uğraş alanlarına giren bu ve benzer kavramların eğitiminde; didaktik eğitimden daha çok somut bir olgu üzerinden soyut kavramların tartışılması, sıklıkla olguların analiz edilmesi yöntemi kullanılmaktadır. Bazen öğrencinin tanıklık ettiği durumlar, gözlemler üzerinden yürütülen tartışmalar, kimi zaman ise medyada yer almış haberlerin analizi ile yapılabilmektedir. Seçilen örnek olaylar görsel, yazılı birçok kaynaktan derlenebileceği gibi sinema filmleri de birer uzun vaka olarak ele alınabilmektedir. Örnek olay seçimi, film gösterimi şeklinde olursa; filmi izleyen kişinin, yaratılan illüzyon ile filmin içine girebileceği, kendisiyle(doktor rolü) veçevresiyle(hasta/hasta yakını rolü) özdeşlikler kurabileceğine ilişkin görüş hakimdir (12-17). Gençlerin teknoloji ile güçlü ilişkisi nedeniyle son yıllarda sinema filmlerinin 'örnek olay incelemesi metodu' olarak ele alınıp bütün öğretim kademelerinde giderek artan oranda kullanıldığ 1 görülmektedir (18-20). Bu artışa sinema filmlerinin vaka tartışması olarak verilen yazılı ya da sözlü tanımlamalardan daha fazla ayrıntı içermesi ve görsel olarak çok zengin oluşunun etkisi vardır. Çünkü görsel ve işitsel sunum sayesinde vaka canlanır, hastalık/ hasta /durum/olay sadece bir tanım olmaktan çıkar ve yaşayan bir deneyime dönüşür. Özellikle soyut kavramları daha çok 
içeren konuları öğrenci ile soyutluktan çıkarıp somutlaştırılabilir hale getirmek kolaylaşabilir (21-22). Bu alanda 1979 y1lında sinema seminerinin psikiyatri eğitiminde kullanışlı bir metod olabileceği hakkında yayınlanan makale bu konudaki ilk çalışmalardan birisidir (23). Sine-eğitim (Cinemeducation) kavramı ise daha yakın zamanda ortaya konmuştur ve tıp eğitimi veya uzmanlık eğitimi sırasında farklı tematik alanlarda filmler/kısa filmler/ video klipler gösterilmesiyle faydalı bir eğitim modeli oluşturabileceği bildirilmiştir (24). Örneğin; "İçimdeki Deniz" filmi; üzerinden öğrenci ile yardımlı intihar, ölme hakkı, yaşam sonu kararları gibi soyut konular somut olay ve insanlar üzerinden tartışılabilir. Benzer biçimde "The Hospital" filmi; hekimlik mesleği ve tıbbın değerleri ile hekimlik erdemleri üzerinden tartışmaların sürdürülebileceği uygun bir senaryoya örneğidir (16). "Wit" filmi; özellikle hasta hekim ilişkisi, acı gerçeğin söylenmesi, yaşamın sonu, ilerisi için talimatlar ve ölüm konularını (25), "My Sister Keeper" filmi ise insan amaç ve araç ilişkisi, 1smarlama bebek, canlidan organ- doku naklinde etik konuları içeren senaryosuyla tıp etiği konuları için oldukça önemli filmlerdir (26). Bu filmler gibi tematik olarak tıp disiplinini konu edinen filmler sayesinde tıp alanındaki değer sorunlarının; başlıca karakterler üzerinden anlatımıyla, kapsamlı ve başarılı yazılmış bir olgu metininden çok daha etkili, kapsamlı ve akılda kalıcı anlatısıyla işitsel ve görsel hafızaya katkısı sayesinde akılda kalabilmektedir (16). Dünyanın çeşitli bölgelerinde eş zamanlı olarak tematik filmlerle yürütülmüş ve olumlu geri bildirimler alınmış eğitim programları bunlara iyi örnek niteliğindedir (25). Örneğin; Wit filmi Amerika Birleşik Devletleri başta olmak üzere Avrupa ve Uzak Doğunun çeşitli ülkelerinde araştırma projesi konusu olarak seçilmiştir ve bu filmin özellikle yaşam sonu konuları eğitimine olumlu katkısından söz eden sonuçları yayınlayan çok sayıda çalışma bulunmaktadır $(27,28)$. Ülkemizde de tıp fakültesi birinci sınıf öğrencileri ile yürütülen bir çalışmada, araştırmacılar yaşamın sonu konularını ve hasta hekim ilişkisini bu film üzerinden sorgulamış ve çalışmanın sonucunda bu tür sinema filmlerinin yenilikçi, etkili bir eğitim yöntemi olduğunu belirtmişlerdir (29). Benzer bir biçimde 2009 yılında Tayland' da tıp fakültesi ikinci sınıf öğrencilerine beş ayrı film aracılığıyla yürütülen çalışma sonuçları; profesyonelliği kavrama, hastalık, hastalar ve ailelerinin hastalıktan nasıl etkilendiği gibi konuları öğrenmeye katkısını ve öğrencilerin bu konularda eleştirel düşünme becerilerinin daha da geliştiği yönünde sonuç bildirmişilerdir (30). Tıp fakültesi dışında kalan diğer sağlık disiplini öğrencilerinin eğitimi için de film kullanımına ilişkin çeşitli çalışmaların yapıldığı ve benzer olumlu sonuçların paylaşıldığ1 görülmektedir (31-34).

Bilindiği gibi özellikle klinik öncesi eğitimde etik ve profesyonel değerlerin tartışılacağı bir program "iyi hekimlik" eğitimini amaçlayan bir tıp eğitimi için vazgeçilmezdir. İyi hekimlik eğitimin temelini hasta hekim ilişkisinin etik dayanakları ve hekimin koruması gereken değerler ile hekimin sahip olması gereken erdemler oluşturmaktadır. $\mathrm{Bu}$ bağlamda hekimlik mesleğini, hasta hekim arasındaki güçlü güçsüz ilişkisini, hasta olmanın nasıl bir şey olduğunu, empatik yaklaşımı, kötü haberin verilmesini ve hekimin sahip olması gereken erdemleri, sorgulatan içeriğe sahip olan "The Doctor" filmi bu konudaki iyi örneklerden birisidir. Başarılı, ünlü ve zengin bir kalp damar cerrahı olan Dr. Jack McKee karakteri üzerinden öykülenen film; sahip olduğu özelliklerin etkisiyle hasta-hekim ilişkisini hekim merkezli sürdüren bir doktorun, kendisine kanser teşhisi 
konulmasıyla hayatı ve mesleğini yeniden sorguladığı senaryosuyla dikkat çekmektedir. Bu süreçte Dr. Jack McKee hasta gözüyle klinik ortamda hekim ve hasta arasındaki güçlü- güçsüz ilişkisinin hasta rolüyle nasıl değiştiğini, hastalık ve başarı merkezli yaklaşımın iletişime olumsuz etkisini, bütüncül ve hasta merkezli yaklaşımın empati kurmaya katkısını, hekimlik mesleğinin profesyonel değerlerinin neler olduğunu ve iyi bir hekimin sahip olması gereken erdemleri değerlendirme firsatı bulabilmektedir $(13,16)$. $\mathrm{Bu}$ film senaryosu itibariyle özellikle klinik öncesi öğrencilerle; profesyonellik kavramını ve bu konuda yaşanan değer çatışmalarını, hekimin arzu edilen özellikleri, iyi hekimlik imajı, hekim-hasta ilişki, etkin iletişim gibi konuları tartışmaya açabilmeyi kolaylaştırabilecek özelliktedir. Özellikle filmin seçilmiş belli başlı sahneleri "örnek olay incelemesi” olarak kullanılabilir içeriğe sahiptir. Alexander bu filmi konu aldığı makalesinde filmin tıp eğitimi sırasında: 1) Görüşme teknikleri 2) Kötü haber verme 3) Son dönem hastalığın psikososyal etkisi 4) İş- günlük hayat arasındaki denge (tıp evliliği) 5) Tıptaki kültürel çatışmalar 6) Hastane bürokrasisi ve hasta tatmini 7) Tiptaki adli konular 8) Cinsiyet ve tıp 9) Etkili uzmanlık eğitimi gibi farklı konularda kısa film kesitleri şeklinde kullanılarak faydalı olabileceğini bildirmektedir (35).

Bu gerekçelerle bu çalışmada; uzun vaka olarak seçilen The Doctor filmi, üzerinden klinik öncesi süreçteki tıp fakültesi öğrencilerinin; hastanın güçsüz tarafı hekimin güçlü tarafı temsil ettiği hasta hekim ilişkisinde, hekimin yakalandığ deneyimlediği hastalık sürecini; kötü haberi verme; empatik yaklaşım sergileme; hasta olan bir meslektaşıyla kuracağı ilişkinin doğası ve hastalık sürecini deneyerek öğrenme gibi karmaşık konularda hasta hekim ilişkisinin olumlu ve olumsuz yönleri ve ilişkisinin etik boyutu hakkındaki öğrencilerin görüşlerini belirlemek amaçlanmıştır. Böylelikle henüz tıp eğitiminin başlangıcında olan öğrencilerin iyi bir hekimin sahip olması gereken temel özellikleri hakkındaki düşüncelerine ilişikin ipuçlarına da ulaşılabileceği düşünülmektedir.

\section{GEREÇ VE YÖNTEM}

Araştırmanın Örneklemi: Muğla Sitkı Koçman Üniversitesi Tıp Fakültesi bir ve üçüncü dönem öğrencileri arasından film gösterimine gelen ve çalışmaya katılım konusunda gönüllü olan öğrenciler oluşsturmaktadır. Çalışma gönüllülük bildiren ve filmi izleyip çalışma formunu eksiksiz dolduran öğrencilerle yürütülmüştür. Çalışma sürecinde yedi ayrı zamanda gösterilmiş olsa da dönem iki öğrencileri ders programlarındaki yoğunluk nedeniyle filmi izleyememişler ve çalışma dişında tutulmuşlardır

Verilerin Toplanması: Çalışma için; Muğla Sitkı Koçman Üniversitesi İnsan Araştırmaları Etik Kurulundan (7/4/2016 tarih ve 43- 42 say1) etik kurul onayı ile Muğla Sitkı Koçman Üniversitesi Tıp Fakültesi Dekanlığından kurum izini (say1: 51250702-604.01.00.00337 ve Tarih: 10/3/ 2016) alınmıştır. Proje başvurusunun Bilimsel Araştırma Biriminin onaylamasından sonra çalışmanın uygulaması 2016 yılı Ekim ayında başlamıştır. Tıp fakültesi öğrencilerine The Doctor isimli sinema filmi yedi ayrı gün ve saatte izletilmiştir. Film gösterimleri öncesinde ilgili film afişi; proje başlığı ve amacı belirtilerek, gösterim yer ve saat bilgisiyle fakültenin ilan panolarına asılarak öğrencilerin bilgilenmesi sağlanmıştır. Film gösteriminden önce öğrenciler araştırma konusu ve yöntemi hakkında tekrar bilgilendirilmiştir. Çalışmaya katılımda gönüllüğün esas olduğu bir kez daha hatırlatılmıştır. Filme ilişkin çeşitli sahnelerde 
öğrencilere sorgulama formları dağıtılmış ve açık uçlu sorulara yanıtlar vermeleri istenmiştir. İlk form filmin yirmi dördüncü ve ikinci form final sahnesi için araştırmacılar tarafından ilgili dakikalarda öğrencilere dağıtılarak öğrencilerin konu hakkındaki görüşleri alınmıştır.

Veri Toplama Aracı: Araştırmada iki adet sorgulama formu kullanılmıştır. Bu formlar yarı yapılandırılmış sorgulama formu şeklindedir, araştırmacılar tarafından önceden hazırlanan yapılandırılmış içerik sayesinde öğrencinin yönlendirilmeden görüşlerini açıklayabilmesine olanak sağlanmıştır.

Birinci Sorgulama formu: Dr McKee cerrah Dr Leslie Abbott'u hastalığının tanısı için görmeye gittiği ve Dr Abbott'un Dr McKee'nin malign bir tümörü olduğunu tespit ettiği ve söylediği filmin 24. Dakikasındaki sahnede kullanılmıştır: $\mathrm{Bu}$ sahne sonunda film duraklatılarak öğrencilere: 1. $\mathrm{Bu}$ görüşmenin hangi yönleri iyidir? 2. Bu görüşmenin hangi yönlerinin geliştirilmesi gerekir? Diye iki açık uçlu soru yönetilmiştir.

İkinci Sorgulama formu: Filmin final Sahnesinde Dr. McKee stajyer hekimlere 72 saat boyunca hastanede hasta olarak yatacaklarını bildirdiği sahne kullanılmıştır. Bu sahnede, Dr. McKee stajyer hekimlerin daha duyarlı hekimler olarak yetişmeleri için hastanede yatarak hasta olmayı deneyimlemelerini ve hasta olmanın sıkıntılarını yaşamalarını istemektedir. $\mathrm{Bu}$ sahne sonunda film duraklatılarak öğrencilere: 1 . Sağlık hizmeti verenlerin empatik yaklaşım sergileyebilmeleri için kendilerinin hastane deneyimi yaşamaları gerekli mi? 2. Doğrudan tecrübe edindiğiniz bir hastane deneyiminiz oldu mu? 3. Yaşayarak öğrenme biçimini ile didaktik anlatımla öğrenmeyi kıyasladığınızda ne söylersiniz? Diye üç açık uçlu soru yönetilmiştir.

\section{Verilerin Analizi}

Katılımcıların özel bilgilerini içermeyen formlar değerlendirilmiştir. Değerlendirilen formlardan elde edilen veriler Microsoft Excel 2007 programına sıralı bir şekilde kaydedilmiştir. Açık uçlu sorular, katılımcıların filmin belirlenen bölümündeki tıbbi durum hakkındaki görüşlerini yansıtmaktadır. Katılımcıların açık uçlu sorular üzerinden belirttikleri görüşler daha önceden her soru için belirlenmiş yanıtlara karşılık gelen özelliklerle karşılaştırılmıştır. Açık uçlu sorulara katılımcıların verdikleri yanıtlar, tek bir araştırmacı tarafından değerlendirmiştir bu sayede çalışmada farklı araştırmacıların neden olabileceği karıştırıcı faktörden arındırılması amaçlanmıştır. Elde edilen veriler katılımcıların cinsiyet özelliklerine ve bulundukları sınıflara göre karşılaştırılmıştır. IBM SPSS v20 paket programı ile isteğe bağlı çoklu yanıtlar tablosu oluşturulmuştur, bu program yardımıyla tablo içi karşılaştırmalar için Ki-kare testi kullanılmıştır. $\mathrm{P}<0.01$ istatistiksel olarak anlamlı olarak kabul edilmiştir.

\section{BULGULAR:}

Çalışmaya $58 \quad(\% 59,2) \quad \mathrm{k} 1 \mathrm{z}, \quad 40 \quad(\% 40,8)$ erkek olmak üzere toplam 98 öğrenci katıldı. Öğrencilerin, 74'ü $(\% 75,5)$ birinci sınıf 24'ü (\%24,5) üçüncü sınıftaydı. Çalışmaya katıldığı halde sorulara tam olarak yanıt vermeyen iki öğrenci ise çalışma dışında tutuldu. Filmin 20 ile 24. dakikaları arasında kalan sahne için öğrencilerden, iki soruyu yanıtlamaları istendi. Filmin bu sahnesi, kalp damar cerrahı Dr. Jack McKee'nin larenks kanseri tanısı alarak hasta olma deneyimini yaşadığı önemli bir sahneydi (Dr. McKee aynı hastanede çalışan başarılı bir KBB uzmanı olan Dr. Leslie Abbott'un polikliniğine gider ve Dr. Abbott, Dr. McKee'nin malign bir tümörü olduğunu tespit eder). Öğrenciler, bu sahnede; tanı konuluncaya 
kadar geçen muayene sürecinin olumlu yönleri ile olumsuz/geliştirilmesi gereken yönlerinin neler olduğuna ilişkin kendilerine yöneltilen iki açık uçlu soruyu yanıtladı. Katılımcılar bu sahnede; KBB Hekiminin tanı işlemlerini büyük bir beceriyle yaptığını, hekimin bilimsel bilgisinin çok iyi olduğunu, erken tanıyı başarılı bir biçimde koyduğunu, hasta olan kişinin hekim olması nedeniyle açık iletişim kurarak acı gerçeği doğrudan söylediğini ifade ettiler. Bununla birlikte dört öğrenci ise bu sahnedeki iletişimin hiçbir olumlu yanı olmadığını belirtmiştir (Tablo 1). Öğrencilerin bu sahne hakkındaki görüşleri ile demografik özellikleri arasında anlamlı bir ilişki bulunmamıştır $(\mathrm{P}>0.01)$. Bu sahnenin olumsuz/geliştirilmesi gereken yönleri olarak; hekimin kötü haberi çok başarısız verildiği, empatik yaklaşım sergilenmediği, işlemler sürecinde hastaya bilgilendirme yapılmadığı, hastanın iyi dinlemediği ve meslektaşına gösterilmesi gereken deontolojik yaklaşımın sergilenmediği şeklinde sıralandı (Tablo 1). Bu sahnenin olumsuz yönlerine ilişkin görüşler ile cinsiyet arasında anlamlı fark bulunmaktaydı $(\mathrm{P}<0.01)$. K1z öğrenciler erkek öğrencilerden daha fazla oranda; Hekimin empatik yaklaşım göstermediği görüşündeydi. $\mathrm{Bu}$ durum nedeniyle bir istatistiksel farklılık oluştuğu görülmüştür. Bunun dişında sınıflar arasında öğrencilerin bazı görüşlerinde sayısal farklılık olduğu görülmesine rağmen bu fark istatistiksel açıdan anlamlı değildi $(\mathrm{P}>0.01)$.

Tablo 1. Öğrencilerin Dr. McKee kanser tanısı aldığı sahneye ilișkin görüșleri

\begin{tabular}{|c|c|c|c|c|}
\hline & $\begin{array}{l}\text { Toplam } \\
\text { n (\%) }\end{array}$ & $\begin{array}{l}\text { Erkek } \\
\text { n (\%) }\end{array}$ & $\begin{array}{l}\text { Kiz } \\
\text { n (\%) }\end{array}$ & $P$ \\
\hline \multicolumn{5}{|l|}{ Olumlu Yönü } \\
\hline $\begin{array}{l}\text { Hekim tanı işlemlerini büyük bir beceriyle } \\
\text { yaptı. }\end{array}$ & $57(58,2)$ & $21(52,5)$ & $36(62,1)$ & 0,345 \\
\hline $\begin{array}{l}\text { Hekim FM çok dikkatli ve başarılı } \\
\text { gerçekleştirdi. }\end{array}$ & $53(54,1)$ & $20(50)$ & $33(56,9)$ & 0,501 \\
\hline $\begin{array}{l}\text { Hekim erken tanıyı başarılı bir biçimde } \\
\text { koydu. }\end{array}$ & $53(33,7)$ & $25(62,5)$ & $28(48,3)$ & 0,165 \\
\hline Hekimin bilimsel bilgisi çok iyiydi. & $31(31,6)$ & $14(35)$ & $17(29,3)$ & 0,552 \\
\hline Hekim işlemler sürecince kayıt tuttu. & $2(2)$ & $1(2,5)$ & $1(1,7)$ & 0,789 \\
\hline Hiçbir olumlu yanı yoktu. & $4(4,1)$ & $3(7,5)$ & $1(1,7)$ & 0,156 \\
\hline $\begin{array}{l}\text { Hastanın hekim olması nedeniyle açık } \\
\text { iletişim kurdu. }\end{array}$ & $23(23,5)$ & $7(17,5)$ & $16(27,6)$ & 0,247 \\
\hline \multicolumn{5}{|l|}{ Olumsuz/Geliştirilmesi Gereken Yönü } \\
\hline Hekim kötü haberi çok başarısız verdi. & $44(44,9)$ & $15(37,5)$ & $29(50)$ & 0.221 \\
\hline Hekimin empatik yaklaşımı yoktu. & $41(41,8)$ & $8(20)$ & $33(56,9)$ & $<0.01$ \\
\hline $\begin{array}{l}\text { Hekim meslektaşına deontolojik yaklaşımı } \\
\text { sergilemedi. }\end{array}$ & $26(26,5)$ & $9(22,5)$ & $17(29,3)$ & 0.453 \\
\hline Hekimin iletişim becerileri çok başarısızdı. & $17(17,3)$ & $4(10)$ & $13(22,4)$ & 0.111 \\
\hline $\begin{array}{l}\text { Hekim işlemler sürecinde bilgilendirme } \\
\text { yapmadı. }\end{array}$ & $15(15,3)$ & $4(10)$ & $11(19)$ & 0.226 \\
\hline Hekim hastasını iyi dinlemedi. & $11(11,2)$ & $5(12,5)$ & $6(10,3)$ & 0.740 \\
\hline Diğer & $9(9,2)$ & $6(15)$ & $3(5,2)$ & 0.098 \\
\hline
\end{tabular}


Filmin final sahnesinde asistan hekimlerden hastaları daha iyi anlayabilmeleri için yetmiş iki saat boyunca hastanede hasta olarak yatmalarının istenmesi talebine ilişkin öğrencilerin \%63,3'ü böyle bir deneyime gerek olmadığını ve bu becerinin eğitimle kazanılabilir olduğu görüşünü bildirirmiştir. Yirmi üç $(\% 23,5)$ öğrenci gerek olmadığını ancak katkı sağlayabileceğini düşünmekteydi. Öğrencilerin \%36,7'si ise bu yöntemin kesinlikle etkili olacağını söylemiştir (Tablo 2). Kesinlikle etkili olacak diyenlerin çoğunluğu kız öğrencilerdi ancak istatistiksel olarak anlam yaratabilecek bir farklı11k izlenmedi $(\mathrm{P}>0.01)$. Hastaneye yatma konusunda kendi deneyimi olup olmadığı ve bu deneyimin empati kurabilmek için etkili olup olmadığına ilişkin diğer iki soruya öğrencilerin verdikleri yanttlara göre; hastalık deneyimi olan ve bu deneyimin işe yaradığına inananlar $\% 40,8$ oranındaydı. Böyle bir deneyim yaşamayan ancak böyle bir deneyim yaşasaydı olumlu bir katk1 sağlayacağına inanlar olduğu gibi bu konuda karasız olup bir görüş bildiremeyeceğini ifade eden öğrencilerde bulunmaktaydı. Buna karşın böyle bir kişisel deneyime gerek olmadığ 1 ve bu deneyimin empati yapmayla bir ilişkisi olmadığını düşünenlerde $\% 23,5$ oranındaydı (Tablo 2).

Tablo 2. Öğrencilerin kişisel deneyimin empatik tutumla ilişkisi hakkında görüşleri

\begin{tabular}{|l|l|l|l|l|}
\hline Görüşler & $\begin{array}{l}\text { Toplam } \\
\text { n (\%) }\end{array}$ & $\begin{array}{l}\text { Erkek } \\
\text { n (\%) }\end{array}$ & $\begin{array}{l}\text { Kız } \\
\text { n (\%) }\end{array}$ & P \\
\hline 72 saat boyunca hastanede hasta olarak yatmak \\
\hline Kesinlikle etkili olur. & $36(36,7)$ & $14(35)$ & $22(37,9)$ & 0.767 \\
\hline Gerek yok ancak katk1 sağlar. & $23(23,5)$ & $10(25)$ & $13(22,4)$ & 0.767 \\
\hline Gerek yoktur bu eğitimle kazanılabilir. & $20(20,4)$ & $8(20)$ & $12(20,7)$ & 0.934 \\
\hline Hayır gerek yok. & $19(19,4)$ & $8(20)$ & $11(19)$ & 0.899 \\
\hline Hastalığı deneyimlemek & $40(40,8)$ & $13(32,5)$ & $27(46,6)$ & 0.164 \\
\hline Deneyimim oldu işe yarıyor. & $16(16,3)$ & $9(22,5)$ & $7(12,1)$ & 0.170 \\
\hline Deneyim yaşamadım iyi olurdu. & $12(12,2)$ & $8(20)$ & $4(6,9)$ & 0.052 \\
\hline Bilemiyorum. & $23(23,5)$ & $8(20)$ & $15(25,9)$ & 0.501 \\
\hline Çok ilgisi olduğunu düşünmüyorum. & $7(7,1)$ & $2(5)$ & $5(8,6)$ & 0.494 \\
\hline Diğer (Bir şey söylemek zor,....).
\end{tabular}

\section{TARTIŞMA}

Öğrenciler fizik muayene ve kötü haberin verilmesi konularının ele alındığı film sahnesinde geçen hasta hekim ilişkisinin olumlu ve olumsuz yönlerini ayırt etmişlerdir. Öğrenciler, iyi bir hekimin tıbbi bilgi-becerisini ortaya koyabilmesini bekleyip, bu özelliği hemen fark edebilmekte ve bu özelliği hasta hekim ilişkisinde güçlü yön olarak görmekteydi. Uygun tanı yöntemini etkin ve beceriyle kullanma, tanı1 erken koyma, etkin tedavi planı yapabilme gibi hekimlik bilgi ve becerileri öğrenciler tarafından olumlu yönler olarak fark edilmiştir. Yapılan çalışmalar özellikle klinik öncesi eğitim sürecinde olan öğrencilerin henüz hasta bakış açısı ile hekimlik algılarını ifade 
etiğini ve bu süreçte bilgi ve beceri yönünden daha çok, hümanisttik değerleri önceleyen hekimlik algılarını ortaya koyduklarını bildirmektedir (36- 38). Bu bağlamda çalışmaya katılan öğrencilerin henüz hekimlik mesleğini öğrenme sürecinin başında olmalarına rağmen yetkin ve donanımlı bir hekimin ayırt edici özelliklerini tespit edebilmiş olmaları önemli bir bulguydu. Ancak, aynı sahnede hekimin hastasıyla kurduğu ilişkiyi "açık iletişim" tanımıyla olumlu bir tutum olarak nitelemiş olmaları da dikkat çekiciydi. Yirmi üç öğrenci hastanın hekim olması sebebiyle hastaya çok fazla bilgi vermeye gerek olmadığı ve aynı nedenle hastalığı ile ilgili acı gerçeği söylemede fazla özene gerek olmadığına inanmaktaydı. Bu inançta olan öğrenciler hekimin bu tutumunu olumlu bir tutum olarak değerlendirilmişti. $\mathrm{Bu}$ durum; temel etik kodlar ve tanımlanmış rehber kurallar 1şığında öğrencinin hasta bireyin profesyonel kimliğine bakılmaksızın bilgilendirme ve özellikle kötü haberi vermede uygun yaklaşımın esirgenememesi gerektiğinin henüz farkında olmadıklarını düşündürmüştür.

Öğrenciler bu sahnenin olumsuz/geliştirilmesi gereken yönlerini de belirlemişlerdir. Öğrencilerin \% 44'9'u tanının erken konulması kadar gerçeğin nasıl söylendiğinin öneminin altını çizmekteydi. Filmdeki sahnede hasta olan bir meslektaşına karşı hekimin tutumunun yanlış olduğunu düşünen çoğunluğunu kızların oluşturduğu öğrenciler, hastanın hekim olmasının hasta hekim arasındaki ilişkiyi daha ayrıcalıklı kılacağını bildirip, ilişkinin daha samimi, daha özel, yakın, güçlü, anlayışlı kardeş gibi özenli ve saygılı olması gerekirken filmdeki bu sahnede hekimin bu tutumu sergilemediği görüşündeydi. Ayrıca yine kız öğrenciler erkeklere göre daha çok oranda bu görüşme sürecinde hekimin empatik bir tutum sergilemediği ve başarısız bir iletişim becerisine sahip olduğu görüşündeydi $(\mathrm{P}<0.01)$.

Tıp Fakültelerinin büyük çoğunluğunda empatik yaklaşıma ilişkin konular mezuniyet öncesi ve sonrası eğitimde, açık ve örtük müfredatta yer almaktadır. Öğrencilerde empatik yaklaşım tutumunu geliştirmek için yoğun uğraş verilmektedir. Çok sayıdaki çalışma cinsiyetin empatik yaklaşımda ayırıcı bir özellik olduğunu ortaya koymuştur. Cinsiyet temelli bu fark tıp fakültesi öğrencileri ile dünya genelinde coğrafya ve kültür fark1 olmaksızın kadınların erkeklerden daha fazla oranda empati puanı aldığını ve bu yaklaşımı daha çok önemsediğini bildirmektedir (3944). Öğrencilerin bu konularda hekimden deontolojik kuraları göz önünde bulunduran ve empatik bir yaklaşım beklemeleri hekimlik sanatının en önemli bileşenlerinden haberdar olduklarını düşündürdü.

Bazı araştırmacılar tıp eğitiminde empatik yaklaşımı artırmak için; hastanın yaşadıklarını aynen yaşamanın bir yöntem olduğu görüşünü öne sürülmektedir (45). The Doctor filmin final sahnesinin konusu olan bu duruma ilişkin soruya, öğrencilerin \% 63,3 ' ü böyle bir deneyime gerek olmadığını ve bu becerinin eğitimle kazanılabilir olduğunu bildirirken öğrencilerden birisi "gebe bir kadını anlamak için mutlaka gebe olmaya gerek olmadığını gibi hastayı anlamak için onun yaşadıklarını yaşamaya gerek te yoktur" örneğini paylaşmıştır. Öğrencilerin \%36,7'si ise böyle bir deneyimin kesinlikle etkili olacağına inanmaktaydı ve cinsiyet bu görüşlerde ayırt ediciydi. Kız öğrenciler erkeklerden daha fazla oranda bu tür zorlayıcı bir deneyimin kesinlikle işe yarayacağı görüşündeydi ancak kız ve erkek öğrenciler arasındaki bu sayısal fark istatistiksel açıdan anlamlı değildi $(\mathrm{P}<0.01)$. Hasta olmadan hastaymış gibi davranmayı uygun görmeyen öğrencilerin daha çoğu gerçek yaşamda hastalık ve hastanede yatma deyimi olan ve bu deneyimin 
işe yaradığı görüşünde olan öğrencilerdi.

Öğrencinin hastaneye yatmanın nasıl bir durum olduğunu anlaması ve dolaylı olarak bu konuda empati kazanması için seçilen sağlıklı tıp öğrencilerinin hastanede belirli bir süre geçirmesine ilişkin çalışmalar bulunmaktadır. Örneğin; ABD yürütülen bir çalışmada hastaneye yatmanın nasıl bir deneyim olduğunu yaşayarak öğrenmeleri amacıyla ikinci sınıf tıp öğrencileri ile yürütülen çalışmada öğrenciler hasta gibi hastanede yatırılmış ve tüm prosedürler kendilerine uygulanmıştır. Gelecekteki tutumlarının bu deneyimle olumlu yönde olacağına ilişkin önerilerde bulunulmuştur (45). Bu çalışmanın kurgusu hipotezine en net eleştiriyi Downie getirerek kurmaca bir durumun çok yanlış olduğu öğrencinin bu çalışmada yaşadığı olumsuzluğun tıp mesleği ve fakülteden soğumasına bile yol açabilecek olumsuzluklar içerdiğini empati kazandırmanın yolunun bu olmadığına vurgu yapmıştır (46). Benzer bir hipotezle ülkemizde yürütülen çalışmada ise çalışmanın katılımcıları emir komuta zincirinin geçerli olduğu bir askeri okulun öğrencileridir (47). Dolayısıyla sağlıklı bireylerin -özellikle öğrencilerin- bu tür bir zorlamaya tabi tutulmaları hipotezin gücünden çok, farklı tartışmalı konuları içermektedir. Modern tıp eğitiminde refleksiyon becerisinin geliştirilmesi için de deneyime dayalı öğrenme sürekli tıp eğitimi dahil olmak üzere tüm eğitim sürecinde önerilmektedir. Bu deneyimlemeden kast edilenin öğrencinin hasta olmaksızın hastane ortamında zorla hastaymış gibi tutulmasının bir öğrenme yöntemi olarak kullanılmasından ziyade empati eğilimini artıran yeni eğitim modelleri ve yöntemlerinin kullanımıdır. $\mathrm{Bu}$ konuda yürütülen çalışmalarda klinik uygulama eğitiminin empati kurabilme yeteneğini geliştirmeye odaklanması gerektiği (48), tıp öğrencileri arasında empati ve diğer hümanist değerleri teşvik etmek için cinsiyet ve öğrenim yıl1, kişilik gibi çeşitli özelliklerin göz önünde bulundurulduğu daha kapsamlı bir müfredatın yapılması gibi öneriler sunulmaktadır (40).

Çalışmanın katılımcısı olan öğrenciler henüz klinik eğitime geçmemiş olmalarına rağmen bu tarz bir olgudaki etik konuları film üzerinden tespit edebilmişlerdir. Hasta hekim ilişkisinin önemli kavramları hakkında sorgulama yapabilmiş görüşlerini ifade edebilmişlerdir. Ayrıca sorgulanan bu iki sahnenin dışında çalışmaya katılan öğrenciler filmin tümünü izlemenin konun tüm detaylarıly ele almalarına katkı verdiğini de ifade etmişlerdir.

Klinik öncesi süreçteki tıp fakültesi öğrencileri; uzun vaka olarak seçilen filmideki hikaye üzerinden mesleki bilgi ve becerinin önemi, kötü haberi verme, empatik yaklaşım sergileme, hasta olan bir meslektaşıyla kuracağ 1 ilişkinin doğası ve hastalık sürecini deneyerek öğrenme gibi karmaşık etik konular hakkında görüş bildirebilmişlerdir. Böylelikle öğrencilerin iyi bir hekimin sahip olması gereken temel özellikleri hakkındaki düşüncelerine ilişikin ipuçları da elde edilebilmiştir. Bu çalışmada tıp eğitimi pratiği sırasında kullanılan bir sine-eğitimi örneği görülmektedir. Bu sine-eğitim örneğinde, tıp etiği kavramları ve hasta hekim ilişkisi değerlendirilmiştir. Aynı zamanda bu örnek, verilen teorik eğitimlerin gözden geçirilerek kabul edilebilir örnek bir vakada tartışılması, elde edilen sonuçların değerlendirilmesi ve öğrenciler arasındaki farklılıkların karşılaştırılması bakımından faydalı olmuştur. Benzer sine-eğitim örneklerinin hazırlanması ile tıbbi teorik eğitimlerinin, pratik örneklerle eğlenceli ve ilgi çekici bir hale getirilmesine yol açacaktır ve tıp eğitimine sanatsal bir bakış açısı kazandırarak eğitimin daha zenginleşmesine yol açabilecektir.

Teşekkür: Bu çalışmaya sağladıkları destek 
için Muğla Sitkı Koçman Üniversitesi Bilimsel Araştırmalar Birimi'ne ve ayrıca katkıları için Muğla Sitkı Koçman Üniversitesi Biyoetik Eğitim Uygulama Araştırma Merkezi (BIYOMER) yönetim kurulu üyeleri Doç. Dr. Özgür Tanrıverdi, Dr. Öğr. Üyesi Hatice Demir Küreci, Dr. Öğr. Üyesi Rabia Kılınç'a teşekkür ederiz.

Maddi Destek: Bu çalışma Muğla Sitkı Koçman Üniversitesi Bilimsel Araştırmalar Birimi tarafindan (01-09-2016 tarih ve Proje No16/122) desteklenmiştir.

\section{KAYNAKLAR}

1. Fox E, Arnold RM, Brody B. Medical ethics education: past, present, and future. Acad Med 1995; 70(9): 761-769.

2. Coulehan J, Williams PC. Conflicting professional values in medical education. Camb Q Healthc Ethic 2003; 12(1): 7-20.

3. Jackson M, Calman K. Medical Education past, present and future. Med Educ 2006; 40(3): 190-192.

4. Norman G. Medical education: past, present and future. Perspect Med Educ 2012; 1(1): 6-14.

5. Dereboy İF, Gürel M, Erpek S, Şavk O. Tıp eğitiminde tam entegrasyona doğru: Menderes deneyimi. Toplum ve Hekim 2001; 16(3):194204.

6. Civaner M, Okuyan ZA, Şemin S. Dokuz Eylül Üniversitesi Tıp Fakültesi'nde mesleksel değerler ve etik eğitimi: üç yıllık deneyim, sorunlar ve öneriler. Tıp Fakültesi Dergisi 2001; Özel Sayısı: 57-61.
7. Turan-Özdemir S. T1p eğitimi ve standartlar. Uludağ Üniversitesi Tıp Fakültesi Dergisi 2005; 31(2): 133-137.

8. Kurdak H, Altıntaş D, Doran F. Medical education in Turkey: past to future. Med Teach 2008; 30(8): 768-773.

9. Sayek İ, Odabaşı O. Türk Tabipleri Birliği Mezuniyet Öncesi Tıp Eğitimi Raporu 2010. Türk Tabipleri Birliği Yayınları: ISBN 978-6055867-38-6

10. Elçin M, Odabaşı O, Sayek İ. İyi hekimlik uygulamalar1. Acta Medica 2004; 35:179-181.

11. Akın BA, Yakıncı MC. Hastalık konulu anlatı filmleriyle tıp eğitimi. Çocuk Sağlığı ve Hastalıkları Dergisi 2013; 56(4): 208-217.

12. Self DJ, Baldwin DC, Olivarez M. Teaching medical ethics to first-year students by using film discussion to develop their moral reasoning. Acad Med 1993; 38 (5): 383-385.

13. Alexander M, Hall MN, Pettice YJ. Cinemeducation: an innovative approach to teaching psychosocial medical care. Fam Med 1994; 26(7): 430-433.

14. Reagan LJ, Tomes N, Treichler PA. (Eds.) Medicine's moving pictures: medicine, health, and bodies in American film and television 2007; University Rochester Press.

15.LumlertgulN, Kijpaisalratana N, Pityaratstian N, Wangsaturaka D. Cinemeducation: A pilot student project using movies to help students learn medical professionalism. Med Teach 2009; 31(7): 327-332. 
16. Colt H, Quadrelli S, Lester F. (Eds.). The picture of health: Medical ethics and the movies. 2011, Oxford University Press.

17. Colt H. Movies and Medical Ethics. In: Macneill P. (eds) Ethics and the Arts. Springer, Dordrecht 2014: 67-78.

18. Mercadé AB. Clinic bioethics and cinematographic narrative. J Med Movi 2008;1(3): 77-81.

19. Öztaş S. Tarih öğretimi ve filmler. Kastamonu Eğitim Dergisi 2008; 16 (2): 543-556.

20. Seren LP, Yakıncı C. Tıp eğitiminde akılda kalıcılığ1 nasıl sağlarız? Çocuk Sağlığ1 ve Hastalıkları Dergisi 2015; 58(3): 123-130.

21. AlarcónWA, Aguirre CM. The cinema in the teaching of medicine: palliative care and bioethics. J Med Movi 2007; 3(1): 32-41.

22. Blasco PG. Literature and movies for medical students. Fam Med 2001; 33(6): 426427.

23. Fritz GK, Poe R0. The role of a cinema seminar in psychiatric education. Am J Psychiat 1979; 136(2): 207-210.

24. Darbyshire D, Baker PA systematic review and thematic analysis of cinema in medical education. Med Humanit 2012;38(1):28-33. doi: 10.1136/medhum-2011-010026

25 Deloney LA, Graham CJ. Developments: Wit: Using drama to teach first-year medical students about empathy and compassion. Teach Learn Med 2003; 15(4): 247-251.
26. Wilson AH, Blake BJ, Taylor GA, Hannings G. Cinemeducation: teaching family assessment skills using full length movies. Public Health Nurs 2013; 30(3):239-245.

27. Purwaningtyas RS. Survival Instinct In Nick Cassavetes's My Sister's Keeper Movie (2009): A Psychoanalytic Approach (Doctoral dissertation, Universitas Muhammadiyah Surakarta). 2013.

28. Klemenc-Ketis Z, Kersnik J. Using movies to teach professionalism to medical students. BMC Med Educ 2011; 11(1): 60-65.

29. Özcakır A, Bilgel N. Educating medical students about the personal meaning of terminal illness using the film, "Wit". J Palliat Med 2014; 17(8):913-917.

30. LumlertgulN, Kijpaisalratana N, Pityaratstian N, Wangsaturaka D. Cinemeducation: A pilot student project using movies to help students learn medical professionalism. Med Teac 2009; 31(7): 327-332.

31. DiBartolo MC, Seldomridge LA. Cinemeducation: teaching end-of-life issues using feature films. J Gerontol Nurs 2009; 35(8): 30-36.

32. Dobbins EH. The impact of end-of-life curriculum content on the attitudes of associate degree nursing students toward death and care of the dying. Teach Learn Nurs 2011; 6(4): 159166.

33. Yoo MS, Park JH, Lee SR. The effects of case-based learning using video on clinical decision making and learning motivation in undergraduate nursing students. J Korean Acad 
Nurs 2010; 40(6): 863-871.

34. Terzioğlu C, Eskiyurt R, Özkan B. (2017). Psikiyatri hemşireliği eğitiminde sinema filmi izletilmesi yöntemi ile öğrencilerin bakım uygulamalarındaki farkındalıklarının araştırılması. Sağlık Bilimleri ve Meslekleri Dergisi 2017; 4(3): 149-161.

35. Alexander M. The doctor: a seminal video for cinemeducation. Fam Med 2002; 34(2):9296.

36. Jahan F, Siddiqui MA, Al Zadjali NM, Qasim R. Recognition of core elements of medical professionalism among medical students and faculty members. Oman Medical Journal 2016, 31(3):196-204.

37. Maudsley G, Williams EM, Taylor D. Junior medical students' notions of a 'good doctor'and related expectations: a mixed methods study. Med Educ 2007; 41(5): 476- 486.

38. Onan A, Elçin M, Turan S. Profesyonel değerlerin tıp fakültesi öğrencilerinin deneyimleri üzerinden değerlendirilmesi. STED 2012; 21 (6): 312-318.

39. Park KH, Roh H, Suh, DH, Hojat M. (2015). Empathy in Korean medical students: findings from a nationwide survey. Med Teac 2015; 37(10): 943-948.

40. Mostafa A, Hoque R, Mostafa M, Rana MM, Mostafa F. Empathy in undergraduate medical students of Bangladesh: psychometric analysis and differences by gender, academic year, and specialty preferences. ISRN psychiatry 2014; 1-7.
41. Grosseman S, Hojat M, Duke PM, Mennin S, Rosenzweig S, Novack D. Empathy, self-reflection, and curriculum choice. Interdisciplinary Journal of Problem-Based Learning 2014; 8(2): 35-41.

42.Chen DC, Kirshenbaum DS, Yan J, Kirshenbaum, E, Aseltine RH. Characterizing changes in student empathy throughout medical school. Med Teach 2012; 34(4): 305-311.

43. Kataoka HU, Koide N, Ochi K, Hojat M, Gonnella JS. Measurement of empathy among Japanese medical students: psychometrics and score differences by gender and level of medical education. Acad Med 2009; 84(9): 1192-1197.

44. Costa P, Alves R, Neto I, Marvao P, Portela M, Costa MJ. Associations between medical student empathy and personality: a multiinstitutional study. PLOS One 2014; 9(3): 1-7.

45. Wilkes M, Milgrom E, Hoffman JR. Towards more empathic medical students: a medical student hospitalization experience. Med Educ 2002; 36(6): 528-533.

46. Downie RS. Towards more empathic medical students: a medical student hospitalization experience. Med educ 2002; 36(6): 504-505.

47. Ortabağ T. Tosun N. Bebiş H, Yava A, Çiçek HS, Akbayrak N. Yatağın diğer tarafi: hemşirelik yüksekokulu birinci sınıf öğrencilerinin eğitim amaçlı hastaneye yatma deneyimleri. Gülhane Tip Dergisi 2010; 52(3):189-197.

48. Park KH, Roh H, Suh DH, Hojat M. Empathy in Korean medical students: findings from a nationwide survey. Med Teach 2015; 37(10): 943-948. 